\title{
Prevalence and Correlates of Overweight and Obesity among School Children in Sohag, Egypt
}

\section{Soumaya El Sayed Ahmed Hadhood ${ }^{1}$, Rasha Abd Elhameed Ali², Montaser Mohamed Mohamed ${ }^{1}$, Eman Soliman Mohammed ${ }^{1}$}

${ }^{1}$ Faculty of Medicine, Pediatrics Department, Sohag University, Sohag, Egypt

${ }^{2}$ Faculty of Medicine, Public Health and Community Medicine Department, Sohag University, Sohag, Egypt

Email: soumayahadhood@yahoo.com,rashaali815@yahoo.com, montaser_dabah@yahoo.com, emansoliman@yahoo.com

How to cite this paper: Hadhood, S.E.S.A., Ali, R.A.E., Mohamed, M.M. and Mohammed, E.S. (2017) Prevalence and Correlates of Overweight and Obesity among School Children in Sohag, Egypt. Open Journal of Gastroenterology, 7, 75-88.

https://doi.org/10.4236/ojgas.2017.72009

Received: January 12, 2017

Accepted: February 17, 2017

Published: February 20, 2017

Copyright () 2017 by authors and Scientific Research Publishing Inc. This work is licensed under the Creative Commons Attribution International License (CC BY 4.0).

http://creativecommons.org/licenses/by/4.0/

\begin{abstract}
Background: Continually rising prevalence of obesity and overweight in children and adolescents is a major public health concern. This is due to its various and serious health hazards on one side and its preventable nature on the other side. This study aims at identification of prevalence of overweight and obesity and its risk factors among children between 6 - 14 years of age in Sohag, Egypt. Method: A cross sectional study was conducted on 711 school children between 6 - 14 years in four months' period from February to May 2016. Weight and height of the studied children were measured to calculate BMI, which was compared with standard Egyptian growth charts for determining overweight and obesity. Then a questionnaire containing data about socio demographic, parental obesity, early life and dietary risk factors was completed by the children's parents. Result: Out of 711 studied children, 117 (16.5\%) were overweight and 104 (14.6\%) were obese. Residing in urban area, having an obese parent or both of them, low level of maternal education, being on formula feeding during early life and lack of fresh vegetables and fruits in diets were significant risk factors for overweight and obesity in the studied children ( $\mathrm{P}$ value $<0.05)$. Conclusion: Improperly educated mothers together with sedentary life style manifested in obesity among the parents and lack of sport practice among children constituted the majors risk factors for childhood obesity. This emphasizes the need for increased health awareness of the community about the importance of proper nutrition and physical activity.
\end{abstract}

\section{Keywords}

Childhood Overweight and Obesity

\section{Introduction}

Obesity is a form of malnutrition that often results from an imbalance between 
food intake and energy utilization. Overweight and obesity in children and adolescents are considered global epidemic. Recent statistics show that, $16 \%$ of children, 6 - 11 years old, are overweight [1]. In actual numbers, the estimate suggested that 150 - 160 million school-age children worldwide were overweight, of which, 35 - 40 million were obese [2]. Statistics also show that, prevalence of overweight continues to increase during the school age and adolescent stages [3].

Obesity in childhood increases the risk of development of metabolic syndrome, diabetes mellitus, cardiovascular and even fatty liver in later life. Asthma, shortness of breath and sleep apnea are common respiratory problems associated with obesity. Children who are obese also have a negative body-image, which leads to lower self-esteem. In Egypt, obesity among school age children constitutes an emerging concern; the Egyptian Medical Association for the Study of Obesity in early 2010 estimates that 15 percent of Egyptian (school-age) children are obese, in comparison with its 1990's estimate of only six percent. The rapid increase in prevalence of overweight and obesity signals that development of strategies to face such problem is a health priority [4].

The etiology of childhood obesity is poorly understood. Obesity is not a single disorder but a heterogeneous group of conditions with multiple causes. Body weight is determined by an interaction between genetic, environmental and psychosocial factors acting through the physiological mediators of energy intake and expenditure. Although genetic differences are of undoubted importance, the marked increase in the prevalence of both overweight and obesity is best explained by behavioral and environmental changes that are results of technological advances [5]. These changes had resulted in increased intake of large quantities of foods high in sugar and energy-rich foods combined with lack of physical exercise. Sedentary lifestyle resulting from spending most of the day watching television, or playing computer or video games is considered a serious factor for obesity. Role of environmental effects on body weight is well noticed in various settings such as at home, in school, and in the community. At home, parents can improve children's food choices and motivate them to practice and have a healthy lifestyle. School also should promote healthy food choices and physical activity among students who spend most of their times in it. As regards communities in the absence of accessible and affordable choices of healthy food and facilities for physical activities as safe side walks, bike paths, and safe parks obesity is a must [4].

\section{Patients and Method}

\subsection{Study Design and Setting}

This is a cross sectional study to determine the prevalence of obesity and its risk factors among children between 6 - 14 years in Sohag, Egypt. Sohag governorate is an agricultural rural region, which produces sugar cane, grains and clover for animal husbandry (United Nations Development Program (UNDP) \& Institute of National Planning Egypt 2010). The total number of population of Sohag, according to Egypt developmental indicator was 4,769,000 citizens. The study was 
conducted in five public primary and two preparatory schools which were selected randomly from public primary and preparatory schools of Sohag city and three nearby villages. It was conducted through a period of four months from February to May 2016.

\subsection{Sample Size}

The sample size was calculated using the EPI-INFO 2002 software (Centers for Disease Control and Prevention (CDC), Atlanta, Georgia, USA; on the basis of a prevalence rate of $13.3 \%$ for obesity among primary school children that was reported by Nora El Saied Badawi, 2012 in Port Said city [6]. With a precision of $3 \%$, a confidence level of $95 \%$, and an error of 0.05 , a minimum sample of 450 students were required. This sample was increased to 700 for proper representation of different age groups in the selected schools.

\subsection{Sampling Technique and Procedures}

Stratified and clustered random sampling technique was employed to select study subjects. Stratification was based on type of school (primary or preparatory), the locality (urban or rural) and grades in each school. Based on the proportion between rural and urban inhabitants in Sohag governorate two schools in Sohag city and five schools in three nearby villages were selected. 200 students were selected from the preparatory schools and 500 from primary schools. As regard the gender all the selected primary and preparatory schools included both girls and boys. Every school was divided into strata based on the grade and in each grade a clustered sample of one class was selected. All students aged between 6 to 14 years were included, while students less than 6 years or more than 14 years were excluded. Also children with chronic illness as well as those on corticosteroid therapy or growth hormone replacement therapy were excluded.

\subsection{Data Collection Procedure}

After agreement of the head of educational directorate of Sohag governorate on conducting this research, data were collected from February to May 2015.

In the first visit to each school, the researcher invited children to participate in the study, sampled them and gave them consent letter for their parents that included basic information about aim of the study, the planned physical examination of the study participants and the questionnaire. This visit took place a day before the second visit in which data were collected. On arrival of the second visit, consent letters from the parents were collected from the children and those who were allowed to participate in the research were gathered in class for measurement of anthropometric then they were given the questionnaire and were asked to take it home to be filled by their parents and give it back to the researcher on the next day.

\subsection{Instrument of the Study: Questionnaire}

A semi-structured, self-administered questionnaire was used. The questionnaire 
had two sections; the first section includes personal information: age, grade, gender, school name in addition to anthropometric measurements. This section was filled in the school by the researcher. The second section which is a reliable questionnaire was filled by one of the parents. This section was concerned about the suggested risk factors of overweight and obesity including maternal education and job, maternal or parental obesity (documented by the mother herself), birth weight of the child, and type of feeding during infancy (whether breast, formula feeding or both). Data about the current dietary habits of the child are also collected including frequency of eating fast food, frequency of drinking sugary fruit juice daily, frequency of eating fresh vegetables and fruits in addition to information about the weekly practice of physical exercises.

\subsection{Anthropometric Measurements}

- Height was measured using stadiometer (Leicester-21400, CECA, UK). Participants were asked to remove shoes before stepping on stadiometer placed on a flat floor along the wall. The students were advised to hold the breath, and maintain an erect anatomical posture. Height measurement was then carefully read to the nearest $0.1 \mathrm{~cm}$.

- Weight was determined using a digital weighing. Measurements were taken with each student in light clothing and without shoes and socks. Weight was carefully read when the point readings stabilized and was recorded to the nearest $0.1 \mathrm{~kg}$.

- The BMI (Body Mass Index) was calculated (body weight in $\mathrm{kg} / \mathrm{height}$ in $\mathrm{m}^{2}$ ).

- By plotting BMI against standard percentile Egyptian curves for each sex, over weight was defined as BMI more than 85th and less than 95th for age and sex, and obesity was defined as BMI more than 95th percentile for age and sex compared to standard Egyptian growth charts.

\subsection{Etical Consideration}

The study protocol was approved by ethical committee of the Faculty of Medicine of Sohag University. A prior consent for the study was taken from the school administration. At the time of the study the parents of each participant were informed about the study protocol and a written consent was obtained to their child's participation and confidentiality was assured.

\subsection{Statistical Analysis}

The statistical analysis was carried out using SPSS software for Windows (version 18.0, Chicago, IL, USA). Sample characteristics were summarized using the mean and the standard deviation (SD) for continuous variables and percentage for categorical variables. Overweight and obesity prevalence rates were calculated using descriptive data, along with corresponding $95 \%$ confidence interval (CI). Chi square test was used to compare distributions of characteristics between overweight, obese and normal and underweight children as appropriate and $\mathrm{P}$ value below 0.05 was considered significant. 


\section{Results}

711 students were successfully enrolled in this study, 323 boys (45.4\%) and 388 girls (54.6\%). The mean age of the studded sample was 10.36 years and the standard deviation was 1.92 years, $36.8 \%$ of the participants were from urban areas while $63.2 \%$ were from rural areas, as shown in Table 1.

Table 2 presents distribution of the studied children as regard prenata, parental, early life and life style factors, about one fifth of the mothers of the studied sample were obese (19.8\%), received high level of education (21.2\%) while more than $84 \%$ were house wives. $92 \%$ of the studied children were full term at birth and $85.5 \%$ had average birth weight. As regard practice of sport more than $72 \%$ of them did not practice sport regulary.

Figure 1 Shows distribution of the studied primary school children as regard BMI. By plotting BMI against standard percentile Egyptian curves, 117 (16.5\%) were overweight and 104 (14.6\%) were obese.

Table 3 shows that high significant association $(\mathrm{P}$ value $=0.004)$ presents between residing in urban areas and both overweight and obesity, as $19.9 \%$ and $13 \%$ of urban school children were obese and overweight respectively compared to $11.6 \%$ and $18.5 \%$ of the rural children. Significant association also presents between overweight and obesity in school children and obesity of one or both parents. More than $20 \%$ children with obese parents were obese compared to $10 \%$ of children with normal weight parents'. More than $25 \%$ of children whose mothers' finished primary level of education only were obese compared to $10.5 \%$ of those finished faculty indicating significant association ( $P$ value $<0.05)$. As regard type of feeding in infancy $31 \%$ of the obese children were on formula feeding compared to $13 \%$ of those who were breast fed either exclusively or with formula and the difference is significant ( $\mathrm{P}$ value $<0.05$ ).

Table 4 indicates presence of very high statistically significant association between not consuming fresh fruits and vegetable daily and overweight and

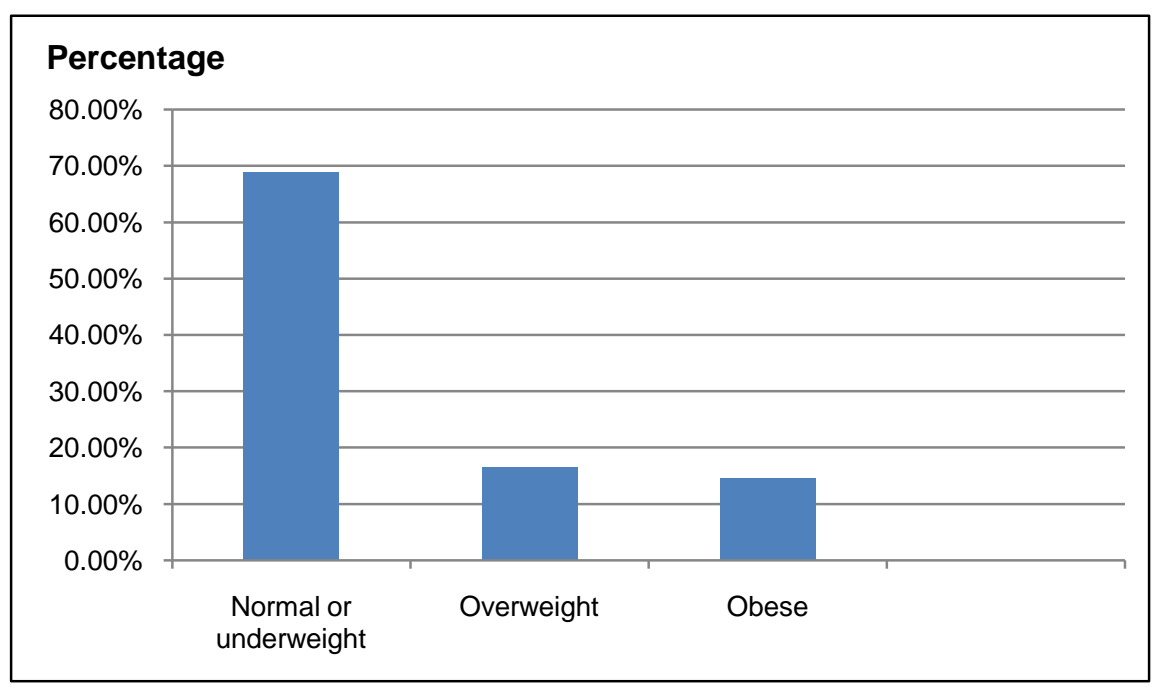

Figure 1. Distribution of the studied children as regard BMI by plotting BMI against Standard Percentile Egyptian Curves. 
Table 1. Sociodemographic data of the studied samples of school children.

\begin{tabular}{|c|c|}
\hline Characteristics & Summary statistics \\
\hline \multicolumn{2}{|l|}{ Age } \\
\hline 6 & $60(8.5 \%)$ \\
\hline 8 & $164(23 \%)$ \\
\hline 10 & $286(40.2 \%)$ \\
\hline $12-14$ & $201(28.3 \%)$ \\
\hline Mean (SD) & $10.36(1.92)$ years \\
\hline Range & $6-14$ years \\
\hline \multicolumn{2}{|l|}{ Gender } \\
\hline Boys & $323(45.4 \%)$ \\
\hline Girls & $388(54.6 \%)$ \\
\hline \multicolumn{2}{|l|}{ Residence } \\
\hline Urban & $262(36.8 \%)$ \\
\hline Rural & $449(63.2 \%)$ \\
\hline \multicolumn{2}{|l|}{ Weight } \\
\hline Mean (SD) & $41.3(1.3) \mathrm{kg}$ \\
\hline \multicolumn{2}{|l|}{ Height } \\
\hline Mean (SD) & $138.6(13) \mathrm{cm}$ \\
\hline \multicolumn{2}{|l|}{ BMI } \\
\hline Mean (SD) & $21(4.3)$ \\
\hline Total & $711(100 \%)$ \\
\hline
\end{tabular}

Table 2. Distribution of the studied children as regard prenata, parental, early life and life style factors.

\begin{tabular}{lcc}
\hline \multirow{2}{*}{ Characteristic } & \multicolumn{2}{c}{ Summary Statistics } \\
\cline { 2 - 3 } & No & \\
\hline Obesity among parents & 465 & $65.4 \%$ \\
No & 141 & $19.8 \%$ \\
Mother only & 57 & $8 \%$ \\
Father only & 48 & $6.8 \%$ \\
Both & & \\
Maternal education & 151 & $21.2 \%$ \\
High & 441 & $62 \%$ \\
Preparatory & 119 & $16 \%$ \\
Primary &
\end{tabular}




\section{Continued}

$$
\text { Maternal job }
$$

Working mother

House wife

Gestational age

$$
\text { Full term }
$$

Pre-term

Post-term

Birth weight

$$
\begin{aligned}
& \text { Average }(2500-3500 \mathrm{gm}) \\
& \text { Low }(<2500 \mathrm{gm}) \\
& \text { High }(>3500 \mathrm{gm})
\end{aligned}
$$

Feeding type

$$
\begin{aligned}
& \text { Breast feeding } \\
& \text { Formula feeding }
\end{aligned}
$$$$
\text { Both }
$$

Frequency of fast food consumption

\section{Occasional}

Once weekly

Twice weekly

More than twice

Sugary juice consumption

Occasional

Once daily

Twice daily

More than twice

Fresh fruits \& vegetables consumption

$$
\text { Occasional }
$$

Once daily

Twice daily

More than twice

Practice of sport

Yes

No
$15.8 \%$

$84.2 \%$

$92 \%$

$5.6 \%$

$2.4 \%$

$85.5 \%$

$7.5 \%$

$6 \%$

$77 \%$

$6.3 \%$

$16.7 \%$

49.45

$23.5 \%$

$10.8 \%$

$16.3 \%$

$78.1 \%$

$13.1 \%$

$4.1 \%$

$4.8 \%$

$3.4 \%$

$16.5 \%$

$25.7 \%$

$54.4 \%$

$27.6 \%$

$72.4 \%$ 
Table 3. Distribution of weight status of the studied children as regard gender, residence and parental and early life factors.

\begin{tabular}{ccccccccr}
\hline & \multicolumn{2}{c}{ Normal weight } & \multicolumn{2}{c}{ Overweight } & \multicolumn{2}{c}{ Obese } & P value \\
\cline { 2 - 6 } & No & $\%$ & No & $\%$ & No & $\%$ & \\
\hline Gender & & & & & & & & \\
Boys & 216 & $(66.9 \%)$ & 59 & $(18.3 \%)$ & 48 & $(14.8 \%)$ & 0.5 \\
Girls & 273 & $(70.3 \%)$ & 58 & $(14.9 \%)$ & 56 & $(14.4 \%)$ &
\end{tabular}

Residence:

$\begin{array}{lccccccc}\text { Urban }(\mathrm{No}=262) & 175 & (66.8 \%) & 34 & (13 \%) & 52 & (19.9 \%) & \\ & & & & & & & 0.004 \\ \text { Rural (No = 449) } & 314 & (69.9 \%) & 83 & (18.5 \%) & 52 & (11.6 \%) & \end{array}$

Obesity among parents

$\begin{array}{lccccccc}\text { No } & 343 & (73.9 \%) & 71 & (15.3 \%) & 50 & (10.8 \%) & \\ \text { Mother only } & 85 & (60.3 \%) & 27 & (19.1 \%) & 29 & (20.6 \%) & \\ \text { Father only } & 35 & (61.4 \%) & 9 & (15.8 \%) & 13 & (22.8 \%) & 0.01 \\ \text { Both } & 27 & (55.1 \%) & 10 & (20.4 \%) & 12 & (24.5 \%) & \end{array}$

Maternal education

$\begin{array}{lccccccc}\text { High } & 110 & (72.4 \%) & 26 & (17.1 \%) & 16 & (10.5 \%) & \\ \text { Preparatory } & 305 & (69.2 \%) & 78 & (17.7 \%) & 58 & (13.1 \%) & 0.003 \\ \text { Primary } & 75 & (63.6 \%) & 13 & (11 \%) & 30 & (25.4 \%) & \end{array}$

Maternal job

$\begin{array}{lccccccc}\text { Working mother } & 80 & (71.4 \%) & 13 & (11.6 \%) & 19 & (17 \%) & \\ \text { House wife } & 410 & (68.5 \%) & 104 & (17.4 \%) & 85 & (14.1 \%) & \end{array}$

Gestational age

$\begin{array}{lccccccc}\text { Full term } & 454 & (69.5 \%) & 107 & (16.4 \%) & 92 & (14.1 \%) & \\ \text { Pre-term } & 26 & (65 \%) & 7 & (12.5 \%) & 7 & (12.5 \%) & 0.8 \\ \text { Post-term } & 9 & (52.9 \%) & 3 & (17.6 \%) & 5 & (29.4 \%) & \end{array}$

Birth weight

$\begin{array}{lccccccc}\text { Average } & 433 & (70.4 \%) & 97 & (15.8 \%) & 85 & (13.8 \%) & \\ \text { Low } & 32 & (60.4 \%) & 12 & (22.6 \%) & 9 & (17 \%) & 0.4 \\ \text { high } & 25 & (58.1 \%) & 8 & (18.6 \%) & 10 & (23.3 \%) & \end{array}$

Feeding type

$\begin{array}{lccccccc}\text { Breast feeding } & 393 & (71.8 \%) & 80 & (14.6 \%) & 74 & (13.6 \%) & \\ \text { Formula feeding } & 21 & (46.7 \%) & 10 & (2.2 \%) & 14 & (31.1 \%) & 0.028 \\ \text { Both } & 76 & (63.9 \%) & 27 & (22.7 \%) & 16 & (13.4 \%) & \end{array}$


Table 4. Distribution of weight status of the studied children as regard dietary and lifestyle factors.

\begin{tabular}{llll}
\hline $\begin{array}{c}\text { Normal weight } \\
(\mathrm{N}=490)\end{array}$ & $\begin{array}{c}\text { Overweight } \\
(\mathrm{N}=117)\end{array}$ & $\begin{array}{c}\text { Obese } \\
(\mathrm{N}=104)\end{array}$ & P value \\
\cline { 1 - 5 } No $\%$ & No $\quad \%$ & No & \\
\hline
\end{tabular}

Frequency of fast food consumption

$\begin{array}{lccccccc}\text { Occasional } & 250 & (71.4 \%) & 52 & (14.9 \%) & 48 & (13.7 \%) & \\ \text { Once weekly } & 118 & (70.2 \%) & 26 & (15.5 \%) & 24 & (14.3 \%) & 0.7 \\ \text { Twice weekly } & 49 & (63.6 \%) & 16 & (20.8 \%) & 12 & (15.6 \%) & \\ \text { More than twice } & 73 & (62.9 \%) & 23 & (19.8 \%) & 20 & (17.2 \%) & \end{array}$

Sugary juice consumption

$\begin{array}{lccccccc}\text { Occasional } & 395 & (71.1 \%) & 83 & (15 \%) & 77 & (13.9 \%) & \\ \text { Once daily } & 53 & (57 \%) & 22 & (23.7 \%) & 18 & (19.3 \%) & \\ \text { Twice daily } & 20 & (69 \%) & 5 & (17.2 \%) & 4 & (13.8 \%) & 0.5 \\ \text { More than twice } & 22 & (64.7 \%) & 7 & (20.6 \%) & 5 & (14.7 \%) & \end{array}$

Fresh fruits \& vegetables consumption

\begin{tabular}{lccccccc} 
Occasional & 13 & $(56.6 \%)$ & 5 & $(21.7 \%)$ & 5 & $(21.7 \%)$ & \\
Once daily & 85 & $(72.6 \%)$ & 15 & $(12.8 \%)$ & 17 & $(16.3 \%)$ & \\
Twice daily & 124 & $(67.4 \%)$ & 32 & $(17.3 \%)$ & 28 & $(15.2 \%)$ & 0.000 \\
More than twice & 268 & $(69.2 \%)$ & 65 & $(16.8 \%)$ & 54 & $(14 \%)$ & \\
Tes of sport & & & & & & & \\
Yes & 143 & $(73 \%)$ & 33 & $(16.8 \%)$ & 20 & $(10.2 \%)$ & 0.19 \\
No & 347 & $(67.4 \%)$ & 84 & $(16.3 \%)$ & 84 & $(16.3 \%)$ & \\
\hline
\end{tabular}

obesity among school children $(\mathrm{P}$ value $=0.000)$, more than fifth $(21.7 \%)$ the children who occasionally eat fresh fruits and vegetables were obese or overweight compared to $14 \%$ and $16.8 \%$ of those who consume it more than two times daily. No significant association was found as regard frequency of consumption of fast food and sugary juices or practice of physical exercises ( $\mathrm{P}$ value $>0.05)$ taking in consideration that only $(27.6 \%)$ of the studied school children practiced sports regularly.

\section{Discussion}

The current study aimed at identification of the prevalence of overweight and obesity among school children and its association with certain socio demographic, parental, early life, dietary and life style risk factors.

In the present study, the overall prevalence of obesity among children from 6 14 years of age was (14.6\%) and the prevalence of overweight was (16.5\%). We 
faced difficulty in comparing our results because of absence of previous studies about the prevalence of obesity in children in Sohag governorate. By comparing our results with studies conducted in Cairo, Alex and Port Said we found that the prevalence of overweight was similar to that of Port Said [6] and Alex [7] but lower than that of Cairo [8]. As regards the prevalence of obesity, it was higher than values reported in Cairo and Alex and similar to values reported in Port Said. These variations might be partially attributed to the difference in the standard curves used for defining obesity and overweight, as [8] used the American standard curve and [7] used the WHO Z-score cutoff points, while in our study and in that of Port Said [6], the local Egyptian BMI charts were used. Variations also can be explained by differences between Alex, and Sohag as regards the society as rural children in the current study represented $63.2 \%$ compared with $25.1 \%$ in Alexandria. The lowest prevalence of obesity in Cairo also linked to the time of conduction of the study which was conducted 10 years ago; many changes have been evolved as regards life style and food consumption since that time.

As regards the prevalence of overweight among school children in the Arab countries, our results are consistent with [9] and [10] in Saudi, [11] in Jordan and [12] in Qatar. On the other hand, our results were much lower than [13] in Kuwait. Concerning the prevalence of obesity, our results were in agreement with [10] [11], but it was higher than [9] [12] and [13]. Apart from Kuwait, all of these studies showed nearly similar rates of overweight, while the prevalence of obesity showed marked variation. As we mentioned before, this could be explained by differences in standard curves used for defining obesity and overweight, in addition to differences in socio economic status between Sohag governorate and those countries. This governorate is one of Egypt poorest governorates that results in a relatively less consumptions of energy dense foods and high consumption of the cheap high fiber diet. In addition, availability of private cars on individual level had led to reduced physical activities of children.

Variations between boys and girls as regards prevalence of overweight and obesity were reported by many studies [7] [14] and [15] although [10] reported presence of variation between boys and girls as regards obesity only but not overweight in Saudi. As in boys, it may indicate health and strength but girls prefer to remain slim. This disagreed with our results, as we found nearly similar rates of obesity among boys and girls while the percentage of overweight was more among boys with no statistically significant difference $(\mathrm{P}$ value $=0.5)$. Meanwhile our results agree with [16] in Egypt and [17] in Turkey. This could be explained by the fact that more than $70 \%$ of the studied children are below or around 10 years. As no much control on weight gain is practiced by female children in this age.

We found that $19.9 \%$ of the studied urban children were obese compared with $11.6 \%$ of the studied rural children while the percentage of overweight was higher among rural children with very high statistically significant difference ( $P$ value $=0.004)$. These results agree with [7] [16] and [18]. This difference could 
be attributed to both dietary variations (absence of fast food restaurants, plenty of fresh fruits and vegetables nearby) and increased physical activity in rural areas as means of transportation are uncommon and children usually walk to schools.

Maternal role in childhood obesity extends beyond genetics; it appears in developing and maintaining healthy dietary habits and life style. This role is affected by her education and availability of time enough for caring her children especially their feeding.

We studied maternal role in obesity and overweight among children by assessing three factors, presence of maternal or paternal obesity, level of maternal education and whether she is a working mother or housewife. In agreement with several studies [6] [14] [16] [17] [19] [20] and [21], we found significant association between obesity among one or both parents and both obesity and overweight among children. $51.9 \%$ of the overweight children and $39.3 \%$ of the obese children had an obese parent or both parents were obese compared with $30 \%$ of the normal weight and underweight children. Significant association was also found between the level of maternal education and childhood overweight and obesity, $25 \%$ of children whose mothers had primary education were obese compared with only $10 \%$ of those whose mothers finished the faculty. This agrees with [17] and disagrees with [16] and [22]. Absence of public awareness about healthy nutrition may explain prevalence of obesity among children of mothers with low level of education. On the contrary, maternal occupation showed no significant association with childhood obesity in agreement with [14] [17] and [23] while [16] and [18] disagreed with us. Several previous studies reported the protective role of breast feeding against childhood overweight and obesity. We found that $31 \%$ and $22 \%$ of formula fed children were obese and overweight respectively compared with $13.8 \%$ and $15.8 \%$ of breast fed children ( $\mathrm{P}$ value $<0.05$ ). This significant association was also reported by [20] [24] [25] and [26].

With rapid economic and technologic development, worldwide life style changes in the form of less physical activity and more consumption of fast and fat rich food predominate. We assessed association between frequency of consumption of fast food, sugary juices, fresh vegetables and fruits and practicing sport and both childhood overweight and obesity. Frequency of consumption of fresh fruits and vegetables was the only significant risk factors. More than $43 \%$ of the children who ate fresh fruits or vegetables occasionally were overweight or obese compared with $30 \%$ of those who ate them twice daily with very high statistically significant difference. This agrees with [6] [27] and [28] and disagrees with [20]. No significant association was found concerning other factors in agreement with [20] [22] and [29] as regards fast food and [29] and [30] as regards sugary juices. On the other hand, [6] [20] [23] and [28] disagree with us. This could be explained by absence of fast food restaurants in rural areas of the study setting where more than $63 \%$ of the study samples were formulated. It is well known that absence of physical activity is an important risk factor of overweight or obesity. On the contrary to many previous studies [6] [17] [23] [28] 
and [31], we found no significant association between overweight and obesity and non practice of sport by children. This may be explained by the fact that $72.4 \%$ of the studied children whether normal weight or overweight do not practice any sport or regular physical exercises as a result of lack of physical activities facilities among these children in agreement with [32].

\section{References}

[1] Pierre, I.B., Huang, C.L., Lee, J.Y. and Lin, B.H. (2005) Dietary Habits, Demographics and the Development of Overweight and Obesity among Children in the United States. Food Policy, 115, 28-30

[2] Lobstein, T. (2010) Prevalence and Trends in Childhood Obesity. Obesity Epidemiology: From Aetiology to Public Health. 2nd Edition, Oxford University Press, 3-16. https://doi.org/10.1093/acprof:oso/9780199571512.003.0001

[3] Mosha, E. and Fungo, S. (2010) Prevalence of Overweight and Obesity among Children Aged 6-12 Years in Dodoma and Kinondoni Municipalities, Tanzania. Tanzania Journal of Health Research, 12. https://doi.org/10.4314/thrb.v12i1.56202

[4] Samy, M.A., Khairy, S.A., Ibrahim, S.A., Matter, M.K. and Hassan, H.K. (2012) Management of Overweight and Obesity in Egyptian School Children-An Intervention Study. The Journal of American Science, 8. http://www.jofamericanscience.org

[5] Kopelman, P.G. (2000) Obesity as a Medical Problem. Nature, 404, 635-643.

[6] El-Said Badawi, N., Barakat, A.A., El-Sherbini, S.A. and Fawzy, H.H. (2013) Prevalence of Overweight and Obesity in Primary School Children in Port Said City. The Gazette of the Egyptian Paediatric Association, 61, 31-36.

https://doi.org/10.1016/j.epag.2013.04.007

[7] El-Shafie, A.M., Hogran, H.H. and Dohein, A.M. (2014) Prevalence of Obesity in Primary School Children Living in Alexandria Governorate. Menoufia Medical Journal, 27, 529-532. https://doi.org/10.4103/1110-2098.145502

[8] Hafez, A.S., EL Amady, M.Y. and Hassan, N.E. (2004) Obesity Profile among Primary School Children in Cairo. Egypt Journal of Community Medicine, 18, 99-170.

[9] El Mouzan, M.I., Foster, P.J. and Al Herbish, A.S. (2010) Prevalence of Overweight and Obesity in Saudi Children and Adolescents. Annals of Saudi Medicine, 30, 203208. https://doi.org/10.4103/0256-4947.62833

[10] Farsi, D.J., Elkhodary, H.M., Merdad, L.A., Farsi, N.M.A., Alaki, S.M., Alamoudi, N.M., Bakhaidar, H.A. and Alolayyan, M.A. (2016) Prevalence of Obesity in Elementary School Children and Its Association with Dental Caries. Saudi Medical Journal, 37, 1387-1394. https://doi.org/10.15537/smj.2016.12.15904

[11] Khader, Y., Irshaidat, O., Khasawneh, M., Amarin, Z., Alomari, M. and Batieha, A. (2008) Overweight and Obesity among School Children in Jordan: Prevalence and Associated Factors. Maternal and Child Health Journal, 13, 424.

[12] Bener, A. and Kamal, A. (2005) Growth Patterns of Qatari School Children and Adolescent Aged 6-18 Years. Journal of Health, Population and Nutrition, 23, 250258.

[13] El-Bayoumy, I., Shady, I. and Lotfy, H. (2009) Prevalence of Obesity among Adolescents (10 to 14 Years) in Kuwait. Asia Pacific Journal of Public Health, 21, 153 159. https://doi.org/10.1177/1010539509331786

[14] Zhang, T., Cai, L., Ma, L., Jing, J., Chen, Y. and Ma, J. (2016) The Prevalence of Obesity and Influence of Early Life and Behavioral Factors on Obesity in Chinese Children in Guangzhou. BMC Public Health, 16, 954. 
[15] Pangani, I.N., Kiplamai, F.K., Kamau, J.W. and Onywera, V.O. (2016) Prevalence of Overweight and Obesity among Primary School Children Aged 8-13 Years in Dar es Salaam City, Tanzania. Advances in Preventive Medicine, 2016, Article ID: 1345017, 5 p. https://doi.org/10.1155/2016/1345017

[16] Hassan, N.E., El-Masry, S.A., Farid, T. and Khalil, A. (2016) Influence of Parental and Some Demographic Characteristics on Overweight/Obesity Status among a Sample of Egyptian Children. Open Access Macedonian Journal of Medical Sciences, 4, 342-347.

[17] Güven, A., Odaci, H., Ozgen, I.T. and Bek, Y. (2008) Effects of Individual Factors on Adolescent Obesity: Study in Turkey. Pediatrics International, 50, 356-362. https://doi.org/10.1111/j.1442-200X.2008.02585.x

[18] Bahbah, M.H., Slama, E.S.I., Ramadan, A.E.M. and Abo Zeed, M.A. (2015) Prevalence of Obesity and Overweight in Primary School Children Living in Menoufia Overnorate, Menouf District. Benha Medical Journal, 32, 73-77. http://www.bmfj.eg.net/text.asp?2015/32/1/73/170572

[19] Koomanaee, S., Tabrizi, M., Naderi, N., Hassanzadeh, R.A., Boloky, M.K. and Dalili, S. (2016) Parental Anthropometric Indices and Obesity in Children. Acta Medica Iranica, 54, 270-275.

[20] Zhang, P., Wu, H., Zhou, X., Lu, Y., Yuan, Z., Moore, J.B. and Maddock, J.E. (2016) The Association between Family and Parental Factors and Obesity among Children in Nanchang, China. Frontiers in Public Health, 4, 162. https://doi.org/10.3389/fpubh.2016.00162

[21] Latorre Román, P.Á., Mora López, D. and García Pinillos, F. (2016) Feeding Practices, Physical Activity, and Fitness in Spanish Preschoolers: Influence of Sociodemographic Outcome Measures. Archivos Argentinos de Pediatria, 114, 441-447. https://doi.org/10.5546/aap.2016.eng.441

[22] Al-Muhaimeed, A.A., Dandash, K., Ismail, M.S. and Saquib, N. (2015) Prevalence and Correlates of Overweight Status among Saudi School Children. Annals of Saudi Medicine, 35, 275-281.

[23] Talat, M.A. and El Shahat, E. (2016) Prevalence of Overweight and Obesity among Preparatory School Adolescents in Urban Sharkia Governorate, Egypt. Egyptian Pediatric Association Gazette, 64, 20-25. https://doi.org/10.1016/j.epag.2015.11.004

[24] Shashaj, B., Graziani, M.P., Contoli, B., Ciuffo, C., Cives, C., Facciolini, S., Rigoni, M.L., Spaterna, S., Taucci, M., Raponi, M. and Manco, M. (2016) Energy BalanceRelated Behaviors, Perinatal, Sociodemographic, and Parental Risk Factors Associated with Obesity in Italian Preschoolers. The Journal of the American College of Nutrition, 35, 362-371. https://doi.org/10.1080/07315724.2015.1070699

[25] Rossiter, M.D., Colapinto, C.K., Khan, M.K., McIsaac, J.L., Williams, P.L., Kirk, S.F. and Veugelers, P.J. (2015) Breast, Formula and Combination Feeding in Relation to Childhood Obesity in Nova Scotia, Canada. Maternal and Child Health Journal, 19, 2048-2056. https://doi.org/10.1007/s10995-015-1717-y

[26] Oddy, W.H., Mori, T.A., Huang, R.C., Marsh, J.A., Pennell, C.E., Chivers, P.T., Hands, B.P., Jacoby, P., Rzehak, P., Koletzko, B.V. and Beilin, L.J. (2014) Early Infant Feeding and Adiposity Risk: From Infancy to Adulthood. Annals of Nutrition and Metabolism, 64, 262-270. https://doi.org/10.1159/000365031

[27] Fletcher, S., Wright, C., Jones, A., Parkinson, K. and Adamson, A. (2016) Tracking of Toddler Fruit and Vegetable Preferences to Intake and Adiposity Later in Childhood. Maternal \& Child Nutrition. https://doi.org/10.1111/mcn.12290

[28] Kepper, M., Tseng, T.S., Volaufova, J., Scribner, R., Nuss, H. and Sothern, M. (2015) Pre-School Obesity Is Inversely Associated with Vegetable Intake, Grocery Stores 
and Outdoor Play. Pediatric Obesity, 11, e6-e8. https://doi.org/10.1111/ijpo.12058

[29] Trier, C., Fonvig, C.E., Bøjsøe, C., Mollerup, P.M., Gamborg, M., Pedersen, O., Hansen, T. and Holm, J.C. (2016) No Influence of Sugar, Snacks and Fast Food Intake on the Degree of Obesity or Treatment Effect in Childhood Obesity. Pediatric Obesity, 11, 506-512. https://doi.org/10.1111/ijpo.12094

[30] Ha, K., Chung, S., Lee, H.S., Kim, C.I., Joung, H., Paik, H.Y. and Song, Y. (2016) Association of Dietary Sugars and Sugar-Sweetened Beverage Intake with Obesity in Korean Children and Adolescents. Nutrients, 8, 31. https://doi.org/10.3390/nu8010031

[31] Souza, C., Silva, R., Assis, A., Fiaccone, R., Pinto, E.D.J. and Moraes, L. (2010) Association between Physical Inactivity and Overweight among Adolescents in Salvador, Bahia-Brazil. Revista Brasileira de Epidemiologia, 13, 1-8.

[32] Sultana, S. and Saleh, F. (2015) Liaquat Ali Childhood Obesity in Primary School Children of Middle and Upper-Middle Income Group in the Capital City of Bangladesh. Food and Nutrition Sciences, 6, 1185-1192.

http://www.scirp.org/journal/fns

https://doi.org/10.4236/fns.2015.613124

\section{Submit or recommend next manuscript to SCIRP and we will provide best service for you:}

Accepting pre-submission inquiries through Email, Facebook, LinkedIn, Twitter, etc. A wide selection of journals (inclusive of 9 subjects, more than 200 journals)

Providing 24-hour high-quality service

User-friendly online submission system

Fair and swift peer-review system

Efficient typesetting and proofreading procedure

Display of the result of downloads and visits, as well as the number of cited articles

Maximum dissemination of your research work

Submit your manuscript at: http://papersubmission.scirp.org/

Or contact ojgas@scirp.org 